REVIEW ARTICLE

\title{
Pathogenesis, Diagnosis, and Management of Metabolic Syndrome: A Comprehensive Review
}

\author{
Vimala Ananthy ${ }^{1}$, Raman Palanyswamy Priyadharsini ${ }^{2}$, Umamaheswari Subramanian ${ }^{3}$
}

\begin{abstract}
Metabolic syndrome is a constellation of abnormalities, such as insulin resistance, central obesity, dyslipidemia, and high blood pressure. The definition and criteria for diagnosing metabolic syndrome keep changing and are a topic of debate. Regardless of the true criteria, the collection of these metabolic abnormalities increases the risk of developing type II diabetes mellitus and cardiovascular disease. The pathogenesis of metabolic syndrome involves the deregulation of various metabolic pathways involved in fatty acid metabolism, mitochondrial function, and glucose utilization. Metabolic syndrome is associated with an increased risk of other disorders, like nonalcoholic fatty liver, polycystic ovarian disease current terminology (PCOS), Alzheimer's disease, lipodystrophy, and Cushing's syndrome. The management of metabolic syndrome begins with lifestyle modification followed by pharmacotherapy of the individual component of metabolic syndrome. Weight reduction and lifestyle modification remains the mainstay of therapy of metabolic syndrome. Since insulin resistance is the major pathology behind the disease, insulin sensitizers, such as metformin and thiazolidinedione, are of great use. Hypolipidemic and antihypertensive drugs are used for treating other components of this syndrome. With the development in the field of molecular biology, the therapeutic targets for treating the individual components of the syndrome have been refined. This review focuses on the etiopathogenesis of metabolic syndrome and highlights the current and future therapeutic targets.
\end{abstract}

Keywords: Criteria, Hyperlipidemia, Insulin resistance, Metabolic syndrome, Polycystic ovarian syndrome.

SBV Journal of Basic, Clinical and Applied Health Science (2021): 10.5005/jp-journals-10082-03111

\section{INTRODUCTION}

The history of metabolic syndrome dates back to 1988 when Gerald Reaven introduced the concept of "syndrome X" which is an aggregation of cardiovascular risk factors in the same individual. It was then given different names by different scientists, such as "the deadly quartet" by Kaplan and "a secret killer" by Foster. As insulin resistance was the underlying factor, Haffner et al. coined the term "insulin resistance syndrome," which is still being used by some individuals. But at present "metabolic syndrome" is the most widely used term for the aggregation of metabolic abnormalities, which leads to increased cardiovascular risk. An observation by Dr. Vague showed that upper body adiposity as the obesity phenotype was associated with more metabolic abnormalities. These metabolic abnormalities were found to play an important role in the genesis of type II diabetes mellitus and cardiovascular disease. ${ }^{1}$

The metabolic abnormalities include insulin resistance, glucose intolerance, central obesity, dyslipidemia, and increased blood pressure, all of which are well-documented risk factors for cardiovascular mortality. There is a striking increase in the incidence of metabolic syndrome in the past two decades. This increase is due to the global epidemic of diabetes and obesity. One of the estimations shows that around $20-25 \%$ of the world's population is suffering from metabolic syndrome. ${ }^{2}$ These people are two times more at risk to die and three times more at risk to suffer from a heart attack or stroke. For treating metabolic syndrome, it has to be first diagnosed by the physicians. There are many diagnosing criteria, which are being revised frequently, that help in the management of metabolic syndrome.

\section{Definition and Criteria for Diagnosis}

There was a lot of confusion and controversies in defining the criteria for the diagnosis of metabolic syndrome. The World Health Organization (WHO) took the initiative to provide a
${ }^{1}$ Mahatma Gandhi Medical College and Research Institute, Sri Balaji Vidyapeeth, Puducherry, India

${ }^{2}$ Department of Pharmacology, JIPMER Karaikal, Puducherry, India

${ }^{3}$ Department of Pharmacology, Sri Venketeshwaraa Medical College Hospital and Research Centre, Puducherry, India

Corresponding Author: Vimala Ananthy, Mahatma Gandhi Medical College and Research Institute, Sri Balaji Vidyapeeth, Puducherry, India, Phone: +91 9585787226, e-mail: drvimala90@gmail.com

How to cite this article: Ananthy V, Priyadharsini RP, Subramanian U. Pathogenesis, Diagnosis, and Management of Metabolic Syndrome: A Comprehensive Review. J Basic Clin Appl Health Sci 2021;4(2):39-45.

Source of support: Nil

Conflict of interest: None

tool for researchers and clinicians and formulated a set of criteria, following which the National Cholesterol Education Program's Adult Treatment Panel III (NCEP: ATP III) proposed a separate definition. There were also other organizations, like the European Group for the Study of Insulin Resistance, which came forward with similar criteria. The basic structure in all definitions included parameters to assess insulin resistance, hyperglycemia, dyslipidemia, and central obesity.

Among all, NCEP: ATP III was found to be more user-friendly for clinicians for assessing metabolic syndrome. WHO criteria included a glucose tolerance test and test for albuminuria that were not practical for most of the clinicians when compared to NCEP: ATP III, which requires only fasting glucose level. The New International Diabetes Federation definition included waist circumference with ethnicity-specific values, which is more reliable but not commonly used (Tables 1 to 3$)^{3}$

(c) The Author(s). 2021 Open Access This article is distributed under the terms of the Creative Commons Attribution 4.0 International License (https:// creativecommons.org/licenses/by-nc/4.0/), which permits unrestricted use, distribution, and non-commercial reproduction in any medium, provided you give appropriate credit to the original author(s) and the source, provide a link to the Creative Commons license, and indicate if changes were made. The Creative Commons Public Domain Dedication waiver (http://creativecommons.org/publicdomain/zero/1.0/) applies to the data made available in this article, unless otherwise stated. 
Table 1: The new International Diabetes Federation (IDF) definition ${ }^{3}$

According to the new IDF definition, for a person to be defined as having the metabolic syndrome they must have:

Central obesity (defined as waist circumference* with ethnicity-specific values)

Plus any two of the following four factors:

Raised triglycerides

$>150 \mathrm{mg} / \mathrm{dL}(1.7 \mathrm{mmol} / \mathrm{L})$

Reduced HDL cholesterol

or specific treatment for lipid abnormality

$<40 \mathrm{mg} / \mathrm{dL}(1.03 \mathrm{mmol} / \mathrm{L})$ in males

$<50 \mathrm{mg} / \mathrm{dL}(1.29 \mathrm{mmol} / \mathrm{L})$ in females

or specific treatment for lipid abnormality

Raised blood pressure

Systolic blood pressure $\geq 130 \mathrm{~mm} \mathrm{Hg}$ and diastolic blood pressure $\geq 85 \mathrm{~mm} \mathrm{Hg}$

or treatment of previously diagnosed hypertension

Raised fasting plasma glucose $\quad \geq 100 \mathrm{mg} / \mathrm{dL}$

or treatment of previously diagnosed diabetes

*If BMI > 30 central obesity can be assumed, waist circumference need not be measured

Table 2: Adult Treatment Panel III (ATP III) diagnostic criteria for metabolic syndrome ${ }^{3}$

\begin{tabular}{ll}
\hline Risk factor & Defining level \\
\hline Abdominal obesity (waist circumference) & \\
Men & $>102 \mathrm{~cm}$ \\
Women & $>88 \mathrm{~cm}$ \\
Triglycerides & $>150 \mathrm{mg} / \mathrm{dL}$ \\
HDL cholesterol & \\
Men & $<40 \mathrm{mg} / \mathrm{dL}$ \\
Women & $<50 \mathrm{mg} / \mathrm{dL}$ \\
Blood pressure & $>130 / 80 \mathrm{~mm} \mathrm{Hg}$ \\
Fasting glucose & $>110 \mathrm{mg} / \mathrm{dL}$ \\
\hline
\end{tabular}

\section{Etiopathogenesis of Metabolic Syndrome (FLOWCHART 1)}

\section{Lipid Theory}

Excess fatty acid level diminishes the insulin-stimulated glucose utilization. Initially, it was thought that insulin resistance due to fatty acid excess was due to inhibition of glycolysis. Later it was proved that high fatty acid level inhibits insulinstimulated glucose transport and not phosphorylation. Another mechanism is altered fatty acid metabolism which maybe due to mitochondrial dysfunction, increased malonyl-coenzyme (Co) A, or deregulation of AMP-activated protein kinase (AMPK). ${ }^{3}$

Malonyl-CoA inhibits the oxidation of cytosolic longchain CoA, which is the substrate for the formation of triglycerides, diacylglycerol (DAG), and other factors involved in the pathogenesis of the metabolic syndrome. Acetyl-CoA carboxylase (ACC) is the enzyme involved in the formation of malonyl-CoA. Antisense oligonucleotides directed at ACC can decrease the formation of free fatty acid, triglycerides, and ceramide. It was shown by targeting ACC in mice fed with a highfat diet had diminished the development of hepatic steatosis and insulin resistance (Flowchart 2).

It was found that in patients with diabetes associated with obesity, there was decreased mitochondrial function when compared with lean diabetic patients. Whether these mitochondrial abnormalities are due to hereditary factors or due to deregulation of lipid metabolism is yet to be studied. AMPK is an enzyme that plays a key role in both mitochondrial and cellular functions. AMPK is activated during exercise and caloric deprivation and
Table 3: WHO criteria for the diagnosis of metabolic syndrome One of these:

- Type 2 diabetes mellitus, insulin resistance, or impaired glucose tolerance.

Plus at least two of the following:

- Triglycerides $\geq 1.7 \mathrm{mmol} / \mathrm{L}$ and/or $\mathrm{HDL}-\mathrm{c}<0.9 \mathrm{mmol} / \mathrm{L}$ (men) and $<1.0 \mathrm{mmol} / \mathrm{L}$ (women).

- Urine albumin excretion $>20 \mu \mathrm{g} / \mathrm{min}$ or albumin:creatinine ratio $>30 \mathrm{mg} / \mathrm{g}$.

- $\mathrm{SBP} \geq 140 \mathrm{~mm} \mathrm{Hg}$ or $\mathrm{DBP} \geq 90 \mathrm{~mm} \mathrm{Hg}$ or treatment for hypertension.

- Central obesity: $\mathrm{BMI} \geq 30 \mathrm{~kg} / \mathrm{m}^{2}$ or waist:hip ratio $>0.90$ (men), $>0.85$ (women).

phosphorylates ACC, thus inhibiting the formation of malonyl-CoA. It will also concurrently inhibit other enzymes, which are involved in the synthesis of various factors that lead to insulin resistance.

\section{Inflammation and Oxidative Stress}

The proinflammatory state induced by tumor necrosis factor- $\alpha$ (TNF- $\alpha$ ) has been shown to decrease AMPK activity in skeletal muscle. It has recently been proved that anti-inflammatory agents like salsalate activate AMPK and have improved the glycemic status. During inflammation, there is oxidative stress that causes increased levels of leptin, interleukin (IL)-6, and TNF- $\alpha$ and decreased levels of adiponectin and ghrelin, which are all factors associated with dyslipidemia and insulin resistance. Adiponectin is a potent stimulator of AMPK activity, and thus its reduction inversely affects the glucose utility and lipid levels. Leptin is an important hormone involved in this disorder as it increases the fatty acid oxidation and suppresses the appetite through its action on the hypothalamus. The proinflammatory state also increases the tendency for atherogenesis and increases the expression of $\mathrm{NF}-\kappa \mathrm{B}$ by the endothelial cells. Hepatic insulin resistance is seen in patients with high DAG content and protein kinase $C$ activation. ${ }^{4}$

\section{Disorders Associated with Metabolic SYNDROME}

\section{Nonalcoholic Fatty Liver Disease}

Nonalcoholic fatty liver disease (NAFLD) is a spectrum of liver damage ranging from simple steatosis to fibrosis. Insulin resistance increases plasma insulin and glucose levels. This will result in de 


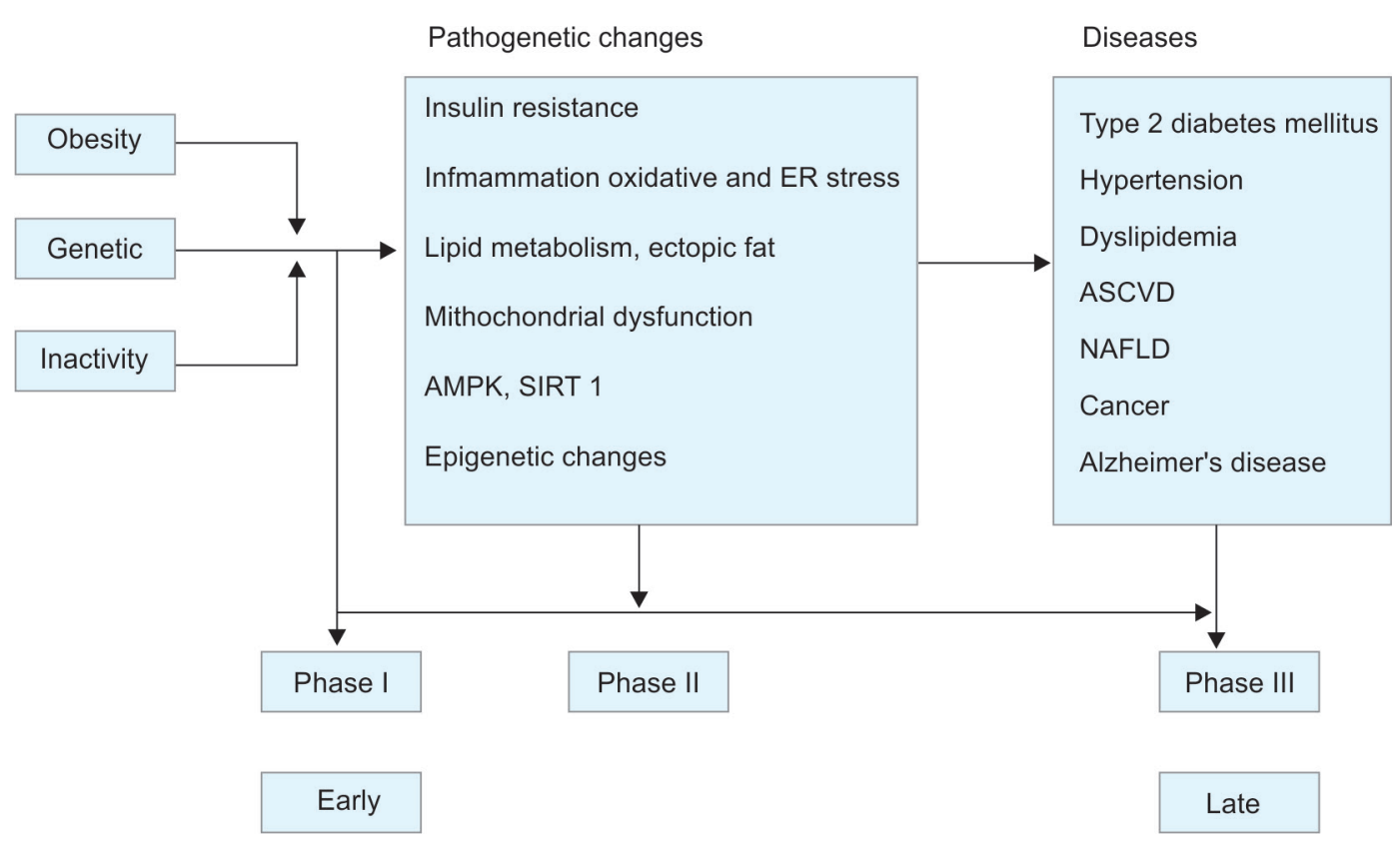

Flowchart 1: Pathogenesis of metabolic syndrome and its three clinical phases. AMPK, AMP-activated protein kinase; SIRT, silent mating type information regulation homolog; ASCVD, atherosclerotic cardiovascular disease; NAFLD, nonalcoholic fatty liver disease; ER, endoplasmic reticulum ${ }^{2}$

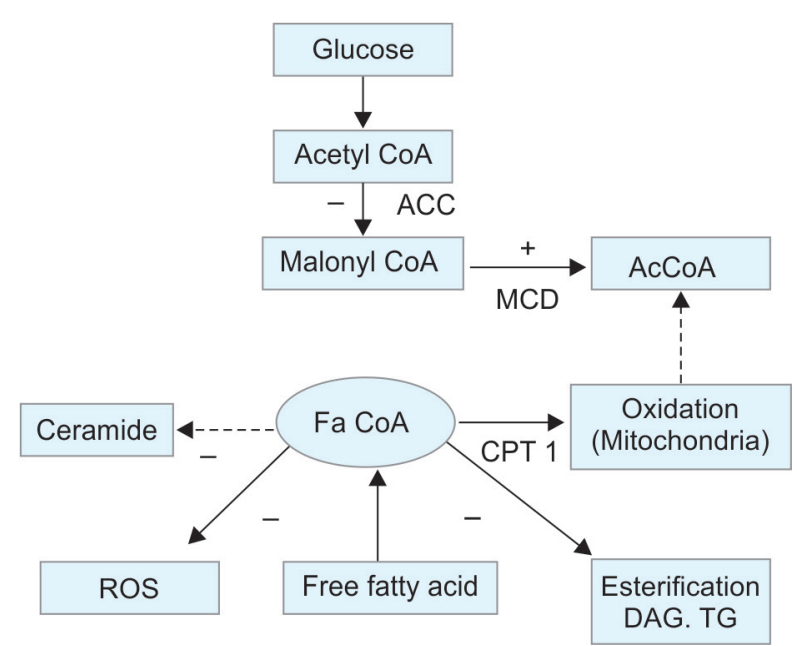

Flowchart 2: AMPK concurrently activates (+) or inhibits (-) multiple aspects of fatty acid and glucose metabolism. ACC, acetyl coA carboxylase; DAG, diacylglycerol; CPT, carnitine palmitoyltransferase; TG, triglyceride; ROS, reactive oxygen species; MCD, malonyl CoA decarboxylase; Fa CoA, fatty acyl coenzyme $\mathrm{A}^{2}$

novo lipogenesis in the liver, resulting in high levels of free fatty acid. Esterification of free fatty acids in the liver leads to triglyceride synthesis and accumulation causing steatosis. Excess dietary fat also results in similar conditions due to the accumulation of triglycerides in the liver. ${ }^{5}$ Thirty-three percent of patients with NAFLD had all components of metabolic syndrome and $90 \%$ had at least one component. Steatosis is 3.4 times more in obese individual when compared to a normal individual. ${ }^{6}$

\section{Polycystic Ovarian Syndrome}

Polycystic ovarian syndrome (PCOS) is characterized by increased ovarian androgen production and deregulated gonadotropin secretion. A study conducted to obtain the prevalence of metabolic syndrome in women with PCOS showed that about $37.5 \%$ had metabolic syndrome. This constituted about one-third of the women attending the infertility clinic. The study also showed that women who were more than 25 years and with a waist: hip ratio of more than 0.85 were the risk factors for metabolic syndrome. ${ }^{7}$ It was found that $93 \%$ of the women had dyslipidemia, which stresses the need for screening these patients for such abnormalities to prevent the genesis of metabolic syndrome.

\section{CANCER}

Carcinogenesis is individually linked to various components of metabolic syndrome, such as obesity, dyslipidemia, and type II diabetes mellitus. Excess weight and adiposity increase the levels of free fatty acid, TNF- $\alpha$, resistin, and decreased levels of adiponectin. This results in insulin resistance and hyperinsulinemia that in turn leads to the reduced liver synthesis of insulin-like growth factorbinding protein (IGFBP-1). ${ }^{8}$ Thus, there is a raised level of free IGF in the circulation that acts on the insulin receptor and is responsible for the proliferation of cell and inhibition of apoptosis. Decreased level of adiponectin leads to an increase in IGF and vascular endothelial growth factor, resulting in angiogenesis and tumor growth. A meta-analysis shows the highest risk of sex-specific cancers like endometrial cancer and breast cancer in postmenopausal women. Other cancers that have a higher magnitude of risk are colorectal cancer, pancreatic cancer and prostate cancer. ${ }^{9}$

\section{Distal Symmetric Polyneuropathy}

Distal symmetric polyneuropathy (DSP) is defined as neuropathic symptoms with at least one confirmatory test (peroneal conduction velocity, heavy monofilament, and vibration threshold). The mechanism involved in the development of neuropathy can be explained by vascular dysfunction as a result of altered mitochondrial function, dyslipidemia, and hyperglycemia. This 
leads to microangiopathy and endoneurial hypoxia, resulting in the accumulation of reactive oxygen species and neuropathy.

In a study conducted in patients with neuropathy symptoms with prediabetes, there was 5.6\% DSP rate among those without any additional component of metabolic syndrome when compared to a rate of $10.6 \%$ DSP rate in participants with additional metabolic syndrome components. ${ }^{10}$

\section{Alzheimer's Disease}

The pathology behind Alzheimer's disease is a deposition of amyloid $A \beta$ peptide and tau proteins in the cerebral cortex. Insulin has been seen to affect $A \beta$ peptide metabolism and is found to increase its secretion. Insulin also increases the extracellular level of $A \beta$ peptide level by inhibiting its degradation by insulin-degrading enzyme. Insulin resistance and hyperinsulinemia, which are the major components of metabolic syndrome, lead to increased levels of amyloid protein and facilitate their deposition in the brain. Another study revealed microstructural damage in white and gray matter in patients with metabolic syndrome, leading to a spectrum of cognitive disorders. ${ }^{11}$

\section{Erectile Dysfunction}

Erectile dysfunction is interrelated to the cardiovascular risk factors involved in the metabolic syndrome. A study conducted in patients with metabolic syndrome shows that 79 to $96 \%$ of patients develop erectile dysfunction and 29 to $66 \%$ of patients with erectile dysfunction have metabolic syndrome. ${ }^{12}$ Visceral obesity and insulin resistance decrease androgen and increase oxidative stress. This leads to endothelial dysfunction and impairment of cavernosal arteries, leading to erectile dysfunction.

\section{Cushing's Syndrome}

Cushing's syndrome is characterized by central obesity, visceral adiposity, impaired glucose tolerance, hypertension, and raised triglyceride levels. Nearly two-thirds of patients with Cushing's syndrome satisfy at least three criteria of metabolic syndrome. High levels of glucocorticoids result in insulin resistance in muscle, adipocyte, and liver. Efficient treatment of hypercortisolism helps to improve all the components of metabolic syndrome. ${ }^{13}$

\section{Other Disorders}

Other important disorders associated with metabolic syndrome are gout, sleep apnea, gallstones, and chronic kidney disease. The increased uric acid level in gout is associated with insulin resistance by causing an increase in the inflammatory response and oxidative stress. Uric acid also decreases adiponectin level, which is involved in the pathogenesis of insulin resistance. The presence of gout in patients with metabolic syndrome has been shown to increase cardiovascular mortality. Clinicians must be conscious about metabolic syndrome while treating patients with gout, which can reduce the cardiovascular mortality. Sleep apnea is associated with metabolic syndrome, and the combination is termed as "syndrome Z". Adipokines, such as adiponectin, ghrelin, and leptin, seem to be deregulated in sleep apnea, which are common abnormalities seen in metabolic syndrome patients. ${ }^{14}$

\section{Current Treatment Strategies}

The management of metabolic syndrome consists of two main therapeutic goals.

- Treatment of the underlying cause ( central obesity, sedentary lifestyle)

- Treatment of the cardiovascular risk factors, which persist despite lifestyle modification

\section{Lifestyle Modification \\ Dietary Management}

The dietary advice mainly concentrates on the amount of carbohydrates, fat, and sodium.

Hypocaloric diet: The most commonly recommended dietary strategy is an energy-restricted diet. A hypocaloric diet produces less energy than the body's demand, resulting in a negative energy balance. Weight loss causes improvement of all the components of metabolic syndrome. As inflammation is strongly associated with obesity and metabolic syndrome, reduction in weight can bring down the inflammatory markers in plasma, such as IL-6. Restriction of calorie has improved the proinflammatory state of the whole body, insulin signal transduction, and insulin sensitivity.

Omega-3 fatty acid: Essential fatty acids constitute omega-3 polyunsaturated fatty acids namely eicosapentaenoic acid (EPA) and docosahexaenoic acid (DHA). A diet rich in these fatty acids has been found to decrease the cardiovascular mortality. Different studies have shown that following a diet rich in omega-3 fatty acid, there was a fall in plasma proinflammatory cytokines, such as IL-6, C-reactive protein, and TNF- $\alpha$. A daily intake of $250 \mathrm{mg}$ of EPA + DHA is recommended for the prevention of cardiovascular mortality. A diet rich in omega-3 fatty acids includes fatty fish, fish oil, walnuts, spinach, and flaxseed oil. ${ }^{15}$

Glycemic index: The quality of carbohydrate is measured by glycemic index. Diet with a high glycemic index tends to increase blood glucose level more promptly and a rapid insulin response, resulting in hypoglycemia. This is associated with a feeling of hunger and increased intake of calorie. A high glycemic index is found in sweetened beverages, juice drinks, soft drinks, cakes, cookies, and candy.

Moderate-high protein diet: Usual recommendation of a normal diet constitutes $55 \%$ of carbohydrate, $15 \%$ of protein, and $30 \%$ of fat. In obese individuals in order to bring down the carbohydrate content, a moderate-high protein diet of $>20 \%$ of protein is recommended. The mechanisms involved are increased thermogenesis and increased satiety. Whenever a hypocaloric diet is advised, it is better to increase the protein content in order to reach the protein energy requirements. ${ }^{16}$

Other recommendations: Other dietary recommendations are high meal frequency, a diet with high total antioxidant capacity, and a Mediterranean diet. Increasing the frequency of meals in small quantities is found to have less fluctuation of glucose level and stable insulin secretion with better appetite control. A diet with high antioxidant content helps in free radical scavenging. WHO recommends fruits and vegetables consumption up to $400 \mathrm{~g} /$ day. Other sources of antioxidant are spices and herbs. A Mediterranean diet was so named because it was observed that countries around the Mediterranean Sea had less incidence of coronary heart disease. 
Their diet comprised of more plant food, olive oil, and less amount of red meat and sweets.

\section{Physical Activity}

A meta-analysis described that moderate and high levels of physical activity had $11 \%$ and $42 \%$ reduced risk of metabolic syndrome. Another study reported that there were significantly lower levels of risk components (in terms of fasting blood glucose, triglyceride levels, and waist circumference) in participants who had one or more per week of physical activity compared to participants who had no physical activity. The beneficial effect of exercise on metabolic syndrome varies with respect to the frequency and intensity of physical activity. The effect was similar in both men and women in improving the components of metabolic syndrome except for triglyceride levels. ${ }^{17}$

It was seen in a similar study that the reduction of triglyceride level following physical activity was $30 \%$ in men in comparison to $2 \%$ in women. In a study conducted in overweight postmenopausal women, interruption of prolonged sitting with 5 minutes of standing or walking significantly reduced postprandial glucose levels, but did not have any effect on triglyceride levels. In a randomized control study, the effect of lifestyle modification, which included a 30-minute exercise daily, reported that there was a significant reduction of the prevalence of metabolic syndrome by $47 \%$. This result was sustained even after a median follow-up period of 4.3 years. ${ }^{18}$ In the Finnish Diabetes Prevention trial, there was a reduction of diabetes by $52 \%$ at a median follow-up of 3.2 years in the intervention group who received individual counseling about weight reduction, physical activity, and intake of saturated fat and fiber diet. ${ }^{19}$

\section{Pharmacotherapy of Metabolic Syndrome Drugs for Hyperglycemia Insulin Sensitizers}

Glucose abnormalities associated with metabolic syndrome include impaired fasting glucose, impaired glucose tolerance test, and type II mellitus. Weight reduction and lifestyle modification can individually improve insulin resistance and should be the first-line management for insulin resistance. Pharmacotherapy must be started when the patient is having both impaired fasting glucose and impaired glucose tolerance or already crossed the diagnostic level for diabetes.

\section{Metformin}

Diabetes prevention program reported that metformin treatment in patients with prediabetes delayed the development of diabetes mellitus and reduced the cardiovascular mortality in patients with metabolic syndrome. It acts by the activation of AMPK, which plays an important role in the pathogenesis of metabolic syndrome. Another mechanism is by inhibiting the absorption of glucose from the intestine and hepatic gluconeogenesis. It is also seen to have an additional advantage in treating associated conditions, such as PCOS and carcinogenesis. It also showed a reduction in waist circumference to a significant level. ${ }^{20}$

\section{Thiazolidinedione}

Drugs from this group act by binding to nuclear peroxisome proliferator-activated receptor (PPAR)- $\gamma$. This nuclear receptor is involved in the regulation of genes associated with lipid and carbohydrate metabolism. It increases the glucose uptake into the muscles and adipose tissues by facilitating the translocation of glucose transporters. It also activates adipocyte hormones especially adipokines, which in turn regulate the AMPK activity. Studies have shown an increase in high-density lipoprotein (HDL) level and variable effect on triglyceride levels in patients with metabolic syndrome. ${ }^{20}$

\section{Other Drugs}

$\alpha$-glucosidase Inhibitor

Another drug used to treat glucose abnormality is $\alpha$-glucosidase inhibitor, acarbose that reduces the absorption of starch, disaccharide, and dextrin. STOP NIDDM trial has reported that acarbose reduces the progression of impaired glucose tolerance to diabetes mellitus and also reduce the development of cardiovascular disease and hypertension. ${ }^{21}$

\section{Glucagon-like peptide-1 Analog}

Even though not an insulin sensitizer, the glucagon-like peptide (GLP)-1 analog addresses almost all the components of metabolic syndrome. Its hypoglycemic effects are mediated by glucosedependent insulin release, suppression of glucagon secretion, and delaying gastric emptying. Exenatide $10 \mathrm{mg}$ s.c twice daily for 30 weeks reduced $\mathrm{HbA} 1 \mathrm{c}$ levels at a range of $0.9-1.6 \% .{ }^{22}$ In a similar study, it was seen that there was a reduction of 24 hours urinary albumin levels by $40 \%$ in comparison with the glimepiride group, which had only $5 \%$ reduction. In the SCALE diabetes trial, liraglutide had a mean weight reduction of $6.4 \mathrm{~kg}$ when compared to the placebo group which had only $2.2 \mathrm{~kg}$ reduction. Thus, the GLP-1 analog is one of the most appropriate treatments for metabolic syndrome. ${ }^{23}$

\section{Drugs for Dyslipidemia}

The recommended treatment goal is to have low-density lipoprotein (LDL)-c levels less than $130 \mathrm{mg} / \mathrm{dL}$, with an option of target level less than $100 \mathrm{mg} / \mathrm{dL}$ in patients with a high risk of cardiovascular morbidity. The lipid status in metabolic syndrome with increased triglyceride levels and decreased HDL levels is termed as atherogenic dyslipidemia. ${ }^{24}$ Drugs that are useful to achieve this target belong to the group of statins and fibrates. Niacin also helps in raising HDL level, but due to its adverse effects, it is less commonly recommended.

Statins act by inhibiting the rate-limiting enzyme in cholesterol metabolism namely hydroxymethylglutaryl-CoA reductase. In a study which was conducted to find the influence of individual risk factor of metabolic syndrome on the efficacy of statin, it was seen that there was $13 \%$ reduction in the LDL-c level in obese individuals when compared to $8.3 \%$ reduction in subjects without abdominal obesity. ${ }^{24}$ Another study conducted to find out the effect of statin on the resolution of nonalcoholic steatohepatitis (NASH) in patients with metabolic syndrome revealed that monotherapy with rosuvastatin had a reduction in the biopsy score for lobar inflammation from 3 to 1, a complete regression of metabolic syndrome, and a large reduction in the plasma glucose. In the same study, a follow-up biopsy taken after 18 months showed no signs of NASH or metabolic syndrome relapse. ${ }^{25}$ Statins also act through their pleiotropic effects on inflammation, cardiovascular events, and endothelial function. 
Fibrates activate PPAR- $\alpha$ and regulate gene expression that affects fatty acid and lipoprotein metabolism in skeletal muscle, liver, and kidney. A meta-analysis on the effect of fibrates on the cardiovascular risk in patients with metabolic syndrome reported $28 \%$ reduction in cardiovascular risk when compared to $5 \%$ reduction in the comparator group. ${ }^{26}$ Another study that focused on the microvascular complications showed that there was a significant reduction in microalbuminuria and macroalbuminuria by fenofibrate. ${ }^{27}$ WHO criteria of metabolic syndrome includes albuminuria as one of the factors for the diagnosis.

\section{Drugs for Hypertension}

The renin-angiotensin system forms an important target for treating various risk factors of metabolic syndrome. Hyperglycemia, cholesterol metabolites, and insulin resistance tend to increase components that are required for the activation of the reninangiotensin system. This may eventually promote inflammation, apoptosis, and oxidative stress. Studies have shown that there is increased expression of angiotensin receptors in patients with hypercholesterolemia. There are also studies which report that there is an upregulation of angiotensin receptor in patients with prolonged hyperglycemia and insulin resistance. Thus, all the components of metabolic syndrome activate the reninangiotensin system, which makes angiotensin receptor blockers and angiotensinogen-converting enzyme inhibitors ideal for treating high blood pressure in these patients. ${ }^{28}$

\section{Drugs for Prothrombotic State}

The metabolic derangements that occur in metabolic syndrome shift the status of blood circulation to a prothrombotic state. The American Heart Association recommends aspirin therapy for those with $10 \%$ risk of coronary event for over 10 years. The majority of patients with metabolic syndrome will have $10 \%$ risk even for young people aged less than 50 years. Thus, aspirin therapy can be recommended especially when the $C$-reactive protein levels are above the normal range. ${ }^{20}$

\section{Drugs for Additional Abnormalities}

PCOS, which is closely related to metabolic syndrome, can result in infertility and has a high chance of progressing to type II mellitus. Metformin had benefit in $34 \%$ of the PCOS patients with metabolic syndrome, out of which $24 \%$ achieved the triglyceride goal, $61 \%$ achieved systolic blood pressure goal, and 60 achieved fasting blood glucose level. ${ }^{29}$ Statins and thiazolidinediones have been shown to improve the histology in nonalcoholic fatty liver disease.

\section{Bariatric Intervention}

This specifically targets the obesity component. This is directed to metabolic syndrome patients with body mass index (BMI) more than $35-40 \mathrm{~kg} / \mathrm{m}^{2}$. A recent meta-analysis reported that bariatric intervention had rapid improvement of all metabolic parameters, but only a limited number of trials had good quality long-term data. It also reported that a reduction in BMI up to $12-14 \mathrm{~kg} / \mathrm{m}^{2}$ decreased the risk of diabetes up to three times and the risk of hypertension and hyperlipidemia up to two times. The most commonly used bariatric interventions are gastric banding, Roux-en-Y gastric bypass, vertical sleeve gastrectomy, and biliopancreatic diversion with duodenal switch. ${ }^{30}$

\section{Future Perspectives}

The novel targets that are being studied for the management of metabolic syndrome are those that affect the basic pathology of adipose tissue malfunction. Two important focuses in this regard are the complement system and the inflammasome. The inflammasome is considered to be the central regulator of early adipose tissue inflammation. Inflammasome member proteins are involved in the induction of insulin resistance and obesity. The final effector molecule in this pathway is IL- $\beta$ whose action can be blocked with IL- $\beta$ antagonists like anakinra, rilonacept, and canakinumab. The complement system has been linked with cardiovascular event recently and its activation is strongly related to the inflammatory reactions in metabolic syndrome. The C3 levels in blood directly correlate with microvascular endothelial dysfunction and have been implicated in the genesis of metabolic syndrome. The terminal complement pathway involves the proinflammatory anaphylatoxin C5. Monoclonal antibody against C5, eculizumab has shown to effectively inhibit the progression of thrombotic microangiopathy. ${ }^{31}$ Newer therapeutic agents target these novel targets for control of the various components of metabolic syndrome.

\section{SUMMARY}

Controversies still remain regarding the concept of metabolic syndrome, but the aggregation of metabolic abnormalities in the same patient warrants meticulous treatment in order to prevent complications. Multiple pathways and molecular mechanism are involved in the pathogenesis of metabolic syndrome. Since early treatment prevents major complications and mortality, it is the clinician's responsibility to rule out metabolic syndrome when there is a grouping of symptoms. Each component must be treated individually and monitored for complications. Lifestyle modification, dietary change, and physical activities are the mainstay of therapy without which other therapies will be unsuccessful. Hence, the management of metabolic syndrome requires proper counseling by a physician and high compliance from patients.

\section{References}

1. Rochlani Y, Pothineni NV, Kovelamudi S, Mehta JL. Metabolic syndrome: pathophysiology, management, and modulation by natural compounds. Ther Adv Cardiovasc Dis 2017;11(8):215-225. DOI: 10.1177/1753944717711379.

2. Beltrán-Sánchez H, Harhay MO, Harhay MM, McElligott S. Prevalence and trends of metabolic syndrome in the adult US population, 1999-2010. J Am Coll Cardiol 2013;62(8):697-703. DOI: 10.1016/j. jacc.2013.05.064.

3. Ruderman NB, Shulman GL. Metabolic syndrome. In: Jameson JL, Groot JD, editors. Endocrinology: adult and pediatric. Elsevier; 2015. p. 752-764.

4. Monteiro R, Azevedo I. Chronic inflammation in obesity and the metabolic syndrome. Mediators Inflamm 2010;2010:289645. DOI: 10.1155/2010/289645.

5. Paschos P, Paletas K. Non alcoholic fatty liver disease and metabolic syndrome. Hippokratia 2009;13(1):9-19.

6. Hamaguchi M, Takeda N, Kojima T, Ohbora A, Kato T, Sarui H, et al. Identification of individuals with non-alcoholic fatty liver disease by the diagnostic criteria for the metabolic syndrome. World J Gastroenterol 2012;18(13):1508-1516. DOI: 10.3748/wjg.v18.i13.1508.

7. Mandrelle K, Kamath MS, Bondu DJ, Chandy A, Aleyamma T, George K. Prevalence of metabolic syndrome in women with polycystic ovary 
syndrome attending an infertility clinic in a tertiary care hospital in south India. J Hum Reprod Sci 2012;5(1):26-31. DOI: 10.4103/09741208.97791.

8. Braun S, Bitton-Worms K, LeRoith D. The link between the metabolic syndrome and cancer. Int J Biol Sci 2011;7(7):1003-1015. DOI: 10.7150/ ijbs.7.1003.

9. Esposito K, Chiodini P, Colao A, Lenzi A, Giugliano D. Metabolic syndrome and risk of cancer: a systematic review and meta-analysis. Diabetes Care 2012;35(11):2402-2411. DOI: 10.2337/dc12-0336.

10. Callaghan BC, Xia R, Banerjee M, de Rekeneire N, Harris TB, Newman $A B$, et al. Metabolic syndrome components are associated with symptomatic polyneuropathy independent of glycemic status. Diabetes Care 2016;39(5):801-807. DOI: 10.2337/dc16-0081.

11. Frisardi V, Solfrizzi V, Seripa D, Capurso C, Santamato A, Sancarlo D, et al. Metabolic-cognitive syndrome: a cross-talk between metabolic syndrome and Alzheimer's disease. Ageing Res Rev 2010;9(4):399-417. DOI: 10.1016/j.arr.2010.04.007.

12. Coban S, Cander S, Altuner MS, Keles I, Gul OO. Does metabolic syndrome increase erectile dysfunction and lower urinary tract symptoms. Urol J 2014;11(4):1820-1824. DOI: https://doi.org/10.1089/ met.2013.0150.

13. Chanson P, Salenave S. Metabolic syndrome in Cushing's syndrome. Neuroendocrinology 2010;1:96-101. DOI: 10.1159/000314272.

14. Calvin AD, Albuquerque FN, Lopez-Jimenez F, Somers VK. Obstructive sleep apnea, inflammation, and the metabolic syndrome. Metab Syndr Relat Disord 2009;7(4):271-277. DOI: 10.1089/met.2008.0093.

15. Iglesia R, Loria-Kohen V, Zulet M, Martinez J, Reglero G, Ramirez de Molina A. Dietary strategies implicated in the prevention and treatment of metabolic syndrome. Int J Mol Sci 2016;17(11):1877. DOI: 10.3390/ijms17111877.

16. Akbaraly TN, Tabak AG, Shipley MJ, Mura T, Singh-Manoux A, Ferrie $\mathrm{JE}$, et al. Little change in diet after onset of type 2 diabetes, metabolic syndrome, and obesity in middle-aged adults: 11-year follow-up study. Diabetes Care 2016;39(3):e29-e30. DOI: 10.2337/dc15-2094.

17. Lee J, Kim Y, Jeon JY. Association between physical activity and the prevalence of metabolic syndrome: from the Korean National Health and Nutrition Examination Survey, 1999-2012. SpringerPlus 2016;5(1):1870. DOI: 10.1186/s40064-016-3514-5.

18. Henson J, Davies MJ, Bodicoat DH, Edwardson CL, Gill JMR, Stensel DJ, et al. Breaking up prolonged sitting with standing or walking attenuates the postprandial metabolic response in postmenopausal women: a randomized acute study. Diabetes Care 2016;39(1):130-138. DOI: $10.2337 / \mathrm{dc} 15-1240$.

19. Pérez-Martínez $P$, Mikhailidis DP, Athyros VG, Bullo M, Couture $P$, Covas $\mathrm{Ml}$, et al. Lifestyle recommendations for the prevention and management of metabolic syndrome: an international panel recommendation. Nutr Rev 2017;75(5):307-326. DOI: 10.1093/nutrit/ nux014.
20. Wagh A, Stone NJ. Treatment of metabolic syndrome. Expert Rev Cardiovasc Ther 2004;2(2):213-228. DOI: 10.1586/14779072.2.2.213.

21. Sugimoto S, Nakajima H, Kosaka K, Hosoi H. Review: Miglitol has potential as a therapeutic drug against obesity. Nutr Metab (Lond) 2015;12:51. DOI: 10.1186/s12986-015-0048-8.

22. DeFronzo RA, Ratner RE, Han J, Kim DD, Fineman MS, Baron AD. Effects of exenatide (exendin-4) on glycemic control and weight over 30 weeks in metformin-treated patients with type 2 diabetes. Diabetes Care 2005;28(5):1092-1100. DOI: 10.2337/diacare.28.5.1092.

23. Chatterjee S, Ghosal S, Chatterjee S. Glucagon-like peptide-1 receptor agonists favorably address all components of metabolic syndrome. World J Diabetes 2016;7(18):441-445. DOI: 10.4239/wjd.v7.i18.441.

24. Rosen JB, Ballantyne CM, Hsueh WA, Lin J, Shah AK, Lowe RS, et al. Influence of metabolic syndrome factors and insulin resistance on the efficacy of ezetimibe/simvastatin and atorvastatin in patients with metabolic syndrome and atherosclerotic coronary heart disease risk. Lipids Health Dis 2015;14:103. DOI: 10.1186/s12944-015-0075-5. Available from: http://www.lipidworld.com/content/14/1/103.

25. Kargiotis K. Resolution of non-alcoholic steatohepatitis by rosuvastatin monotherapy in patients with metabolic syndrome. World J Gastroenterol 2015;21(25):7860. DOI: 10.3748/wjg.v21. i25.7860.

26. Gami AS, Witt BJ, Howard DE, Erwin PJ, Gami LA, Somers VK, et al. Metabolic syndrome and risk of incident cardiovascular events and death: a systematic review and meta-analysis of longitudinal studies. J Am Coll Cardiol 2007;49(4):403-414. DOI: 10.1016/j. jacc.2006.09.032.

27. Ginsberg HN, Elam MB, Lovato LC, Crouse JR, Leiter LA, Linz P, et al. Effects of combination lipid therapy in type 2 diabetes mellitus. $\mathrm{N}$ Engl J Med 2010;362(17):1563-1574. DOI: 10.1056/NEJMoa1001282.

28. De Kloet AD, Krause EG, Woods SC. The renin angiotensin system and the metabolic syndrome. Physiol Behav 2010;100(5):525-534. DOI: 10.1016/j.physbeh.2010.03.018.

29. Kupreeva M, Diane A, Lehner R, Watts R, Ghosh M, Proctor S, et al. Effect of metformin and flutamide on insulin, lipogenic and androgen-estrogen signaling, and cardiometabolic risk in a PCOS-prone metabolic syndrome rodent model. Am J Physiol Endocrinol Metab 2019;316(1):E16-E33. DOI: 10.1152/ ajpendo.00018.2018.

30. Ricci C, Gaeta M, Rausa E, Asti E, Bandera F, Bonavina L. Long-term effects of bariatric surgery on type II diabetes, hypertension and hyperlipidemia: a meta-analysis and meta-regression study with 5-year follow-up. Obes Surg 2015;25(3):397-405. DOI: 10.1007/s11695014-1442-4.

31. Van Greevenbroek MMJ, Schalkwijk CG, Stehouwer CDA. Dysfunctional adipose tissue and low-grade inflammation in the management of the metabolic syndrome: current practices and future advances. F1000 Res 2016;5. DOI: 10.12688/f1000research.8971.1. 